\title{
Early HER2-Positive Breast Cancer: Current Treatment and Novel Approaches
}

\author{
Marija Ban ${ }^{\mathrm{a}}$ Branka Petrić Miše ${ }^{\mathrm{a}}$ Eduard Vrdoljak ${ }^{\mathrm{a}}$ \\ ${ }^{a}$ Department of Oncology, Clinical Hospital Centre Split, School of Medicine, University of Split, Split, Croatia
}

\section{Keywords}

HER2 positivity · Early breast cancer · Neoadjuvant therapy

\begin{abstract}
Background: Trastuzumab significantly improves outcomes in early HER2-positive breast cancer, irrespectively of any prognostic or predictive factors. Unfortunately, about a quarter of patients receiving neoadjuvant trastuzumab experience disease recurrence, revealing the unquestionable need for further improvement of treatment outcomes. Summary: Adding HER2 blockade to adjuvant trastuzumab with pertuzumab and neratinib improves invasive disease-free survival (IDFS), particularly for those at highest risk of recurrence. A shift toward a neoadjuvant strategy for patients with a higher risk of recurrence could result in further treatment optimization. For patients without a pathological complete response $(\mathrm{pCR})$ after the neoadjuvant part of the therapy, a switch to adjuvant trastuzumab emtansine significantly improves IDFS and distant recurrence-free survival and shows a trend towards improved overall survival (OS). On the other hand, for low-risk patients, chemotherapy deescalation should be strongly considered with the use of trastuzumab monotherapy as an anti-HER2 backbone. Key Messages: Neoadjuvant therapy should be offered for a significant proportion of HER2-positive early breast cancer patients with a higher risk of recurrence. Postneoadjuvant treatment should be tailored according to the initial stage of disease and the response to neoadjuvant treatment.
\end{abstract}

\section{Introduction}

Overexpression of human epidermal growth factor receptor 2 (HER2) occurs in 15-20\% of breast cancers and portends an aggressive phenotype and poor patient outcomes [1]. The introduction of HER2-targeted therapies has dramatically changed the prognosis for these patients. The addition of trastuzumab, a humanized monoclonal antibody that binds to the extracellular domain of HER2 receptors, to chemotherapy significantly improved survival in patients with metastatic and early-stage HER2positive breast cancer [2]. Despite the improvement in both disease-free survival (DFS) and overall survival (OS) associated with the addition of trastuzumab to chemotherapy in early HER2-positive breast cancer, long-term follow-up data indicate that approximately 1 quarter of patients still develop disease recurrence [3]. Thus, the focus has been placed on escalating treatment by either combining different HER2-targeted agents or extending the duration of HER2-targeted therapy. In addition to trastuzumab, anti-HER2 drugs that are currently used in early breast cancer treatment include pertuzumab, a monoclonal antibody that blocks another extracellular subdomain of the HER2 receptor, the antibody-drug conjugate trastuzumab-emtansine (T-DM1), and the irreversible pan-HER2 inhibitor neratinib.

However, some patients do not derive sufficient benefit from these additional therapies to overcome the associated toxicities and/or costs. Similarly, the universal use of chemotherapy might not benefit all patients, and 
treatment deescalation through omission or deescalation of chemotherapy has shown promise in clinical trials and is currently being explored further [4].

In this article, the current standard of treatment for early HER2-positive breast cancer, treatment escalation, treatment deescalation and neoadjuvant/adjuvant treatment approaches, and novel approaches with afatinib and neratinib will be discussed.

\section{Neoadjuvant Treatment}

In the past, neoadjuvant treatment was reserved for inoperable, locally advanced, or inflammatory breast cancer in order to improve the rate and quality of surgery [4]. Since that time, the paradigm of neoadjuvant treatment has been changed, and treatment decisions currently include tumor biology in addition to tumor stage. In the context of operable disease, most patients with HER2positive tumors that measure $>2 \mathrm{~cm}$ and/or lymph nodepositive disease receive neoadjuvant treatment [4]. The neoadjuvant concept allows in vivo testing of treatment sensitivity and further personalization of the adjuvant part of therapy and provides a way to receive accelerated approval of new therapies. It is also a valid model for the development of predictive biomarkers and the reduction of patient numbers in clinical trials [5]. The current standard of neoadjuvant therapy for HER2-positive disease is an antracycline/taxane-based chemotherapy in combination with trastuzumab and pertuzumab. This is followed by breast surgery, adjuvant radiotherapy (if indicated), completion of the HER2-directed therapy and, depending on the tumor biology, endocrine therapy.

In HER2-positive breast cancer, pCR rates of $60 \%$ or more can be achieved [6]. Different chemotherapy schedules and HER2-targeted agents, such as trastuzumab, lapatinib, pertuzumab, and T-DM1, have been investigated in the neoadjuvant setting. To achieve a higher rate of pathological complete response (pCR) and, consequently, better long-term outcomes, 2 main strategies were explored: horizontal blockade with anti-HER2-directed antibodies (pertuzumab and trastuzumab) and antibody-cytostatic conjugate (T-DM1) and vertical blockade with tyrosine-kinase inhibitor (lapatinib).

\section{Horizontal Inhibition of the HER2 Pathway}

The first randomized trial investigating neoadjuvant trastuzumab in addition to chemotherapy (NOAH trial) showed a statistically significant improvement in total pCR (38 vs. $19 \% ; p=0.001$ ), a 5 -year event-free survival (EFS) of 58 vs. $43 \%(\mathrm{HR}=0.64 ; 95 \%$ CI $0.44-0.93 ; p=$ 0.016), and a nonsignificant improvement in OS (74 vs.
63\%; HR $=0.66 ; p=0.055)$ [7]. Similarly, in the GeparQuattro study (epirubicin/cyclophosphamide [EC] followed by docetaxel \pm capecitabine in combination with or without trastuzumab), the pCR rate was $31.7 \%$ with trastuzumab and $15.7 \%$ in the reference group [8]. After showing a significant impact on outcomes in a metastatic setting, logically, pertuzumab has been investigated in the neoadjuvant environment $[9,10]$.

The NeoSphere trial first showed that dual horizontal blockade with pertuzumab and trastuzumab in combination with chemotherapy resulted in a significantly improved $\mathrm{pCR}$ rate in the breast in comparison with trastuzumab/chemotherapy combination (pCR: 46 vs. $29 \%$; $p=$ 0.0141 ) without additional cardiotoxicity [10]. In the 5-year follow-up data, patients who achieved pCR had a longer progression-free survival (PFS) compared to patients who did not (i.e., $85 \%$ in patients with pCR vs. $76 \%$ in patients without pCR; $\mathrm{HR}=0.54 ; 95 \%$ CI $0.29-1.00$; $p=0.0141)[10]$.

The TRYPHAENA trial was designed to evaluate cardiac safety in patients treated with neoadjuvant antracycline-containing and antracycline-free chemotherapy regimens with trastuzumab and pertuzumab [9]. The combination of anti-HER2 antibodies was generally well tolerated, regardless of whether it was given sequentially or concomitantly with anthracycline-based or combined with carboplatin-based chemotherapy. The rate of achieved pCR ranges from 57.3 to $66.2 \%$ (Table 1).

After finding a significant impact on HER2-positive metastatic breast cancer outcomes, it was logical to test the value of T-DM1 in neoadjuvant treatment. Unfortunately, the place for neoadjuvant T-DM1 use is still not clearly defined.

\section{Vertical Inhibition of the HER2 Pathway}

With a vision to further improve the results obtained with trastuzumab administration in a neoadjuvant setting, lapatinib was investigated. It was hypothesized that targeting the HER2 pathway from 2 different mechanisms at the same time might improve the response rate and pCR (Table 2). The trials indicated that lapatinib was inferior to trastuzumab in the rate of $\mathrm{pCR}$ and that it was associated with a greater toxicity [14]. Dual HER2 blockade with the trastuzumab/lapatinib combination produced significant improvement in $\mathrm{pCR}$, but unfortunately it did not translate to a significant EFS improvement [14]. In a meta-analysis, in patients receiving a combination of lapatinib and trastuzumab in comparison to trastuzumab only combined with chemotherapy, the absolute improvement in the $\mathrm{pCR}$ rate was 13\% [14].

Newer tyrosine kinase irreversible inhibitors of different HER receptors, such as afatinib and neratinib, have 
Table 1. Neoadjuvant trials with a horizontal HER2 pathway blockade strategy

\begin{tabular}{|c|c|c|c|c|c|}
\hline Trial & Treatment arms & $\begin{array}{l}\text { Rate of pCR } \\
\text { (breast and/or } \\
\text { nodes), \% }\end{array}$ & $\mathrm{p}$ value & EFS/PFS, \% & OS/DFS, \% \\
\hline \multicolumn{6}{|c|}{ Combination with trastuzumab and pertuzumab } \\
\hline \multirow{5}{*}{$\begin{array}{l}\text { NEOSPHERE }[7,10] \\
(n=417 ; \text { phase } 2)\end{array}$} & Docetaxel/trastuzumab & 29 (breast) & & PFS (5 years) & DFS ( 5 years) \\
\hline & & & & 81 & 81 \\
\hline & Docetaxel/pertuzumab/trastuzumab & 45.8 & 0.0141 & 86 & 84 \\
\hline & Pertuzumab/trastuzumab & 24 & & 73 & 80 \\
\hline & Docetaxel/pertuzumab & 16.8 & & 73 & 75 \\
\hline \multirow{2}{*}{$\begin{array}{l}\text { ADAPT (hormone } \\
\text { receptor negative) [11] } \\
(n=134 ; \text { phase } 2 / 3)\end{array}$} & Trastuzumab/pertuzumab/paclitaxel & 90.5 & & $\mathrm{NA}$ & NA \\
\hline & Pertuzumab/trastuzumab & 34.4 & & & \\
\hline \multirow[t]{3}{*}{$\begin{array}{l}\text { TRYPHAENA [9] } \\
(n=225 \text {; phase } 2)\end{array}$} & $\begin{array}{l}\text { Pertuzumab/trastuzumab/FEC followed by } \\
\text { docetaxel/pertuzumab/trastuzumab }\end{array}$ & 61.6 (breast) & & 87 & NA \\
\hline & FEC followed by docetaxel/pertuzumab/trastuzumab & 57.3 & & 88 & \\
\hline & Docetaxel/carboplatin/trastuzumab/pertuzumab & 66.2 & & 89 & \\
\hline \multicolumn{6}{|c|}{ Combination with T-DM1 } \\
\hline \multirow{7}{*}{$\begin{array}{l}\text { KRISTINE [12] } \\
(n=432 ; \text { phase } 3)\end{array}$} & T-DM1/pertuzumab & 44.4 & 0.0155 & 3-year EFS: & NA \\
\hline & & & & $\mathrm{HR}=2.61$ & \\
\hline & & & & $95 \%$ CI $1.36-4.98$ & \\
\hline & & & & 3-year IDFS: & \\
\hline & & & & $\mathrm{HR}=1.11$ & \\
\hline & & & & $95 \%$ CI $0.52-2.40$ & \\
\hline & Paclitaxel/carboplatin/trastuzumab/pertuzumab & 55.7 & & & \\
\hline \multirow{2}{*}{$\begin{array}{l}\text { I-SPY2 }[13] \\
(n=248 ; \text { phase } 2 / 3)\end{array}$} & T-DM1/pertuzumab & 52 & & NA & NA \\
\hline & Docetaxel/trastuzumab & 22 & & NA & NA \\
\hline \multirow{3}{*}{$\begin{array}{l}\text { ADAPT (HR positive) } \\
{[11]} \\
(n=359 ; \text { phase } 2 / 3)\end{array}$} & T-DM1 & 41 & & $\mathrm{NA}$ & NA \\
\hline & T-DM1 + endocrine therapy & 41.5 & & & \\
\hline & Trastuzumab + endocrine therapy & 15.1 & & & \\
\hline
\end{tabular}

been tested in the neoadjuvant setting with results similar to those achieved with lapatinib. In the DAFNE trial patients received a combination of paclitaxel, trastuzumab, and afatinib followed by an EC. The rate of pCR was 49.2\% (95\% CI 38.5-60.1) [24].

Neratinib entered the neoadjuvant setting with the ISPY2 study by the addition of HER2 status to the risk estimation according to gene profiling [26]. In the NSABP FB-7 trial, which investigated neratinib and/or trastuzumab followed by doxorubicin/cyclophosphamide, the pCR rates were $38 \%$ for trastuzumab, $33 \%$ for neratinib, and $50 \%$ in the combination arm [25].

\section{PCR as the Primary Endpoint in Neoadjuvant Clinical Trials}

The pCR rate at the time of surgery is associated with a better prognosis and provides information regarding the responsiveness of the tumor to systemic therapy. A pooled analysis defined $\mathrm{pCR}$ as the strongest discriminator of long-term outcomes for patients in the neoadjuvant setting [27]. Collaborative trials in neoadjuvant breast cancer (CTNeoBC) performed a meta-analysis including 12 neoadjuvant trials with 11,955 patients and follow-up of 3 years and evaluated pCR as a surrogate marker for long-term outcomes [28]. Of all breast cancer subtypes, pCR was associated with EFS ( $\mathrm{HR}=0.48$; $95 \%$ CI $0.43-$ $0.54)$ and $\mathrm{OS}(\mathrm{HR}=0.36$; 95\% CI 0.31-0.42). The highest pCR rates were reported in triple-negative breast cancer and HER2-positive breast cancer. Additionally, the response to neoadjuvant treatment in HER2-positive disease is dependent on the hormone receptor status. A pCR rate of $30.9 \%$ was observed in patients with HER2-positive hormone receptor-positive breast cancer with trastuzumab therapy versus $18.3 \%$ without trastuzumab ( $\mathrm{HR}=$ 0.58 ; $95 \%$ CI $0.42-0.829$ ) and $50.3 \%$ in HER2-positive hormone receptor-negative breast cancer with trastuzumab versus $30.2 \%$ without neoadjuvant trastuzumab $(\mathrm{HR}=0.25 ; 95 \%$ CI 0.18-0.34). Overall, patients with pCR had a longer EFS (HER2 positive: $\mathrm{HR}=0.39 ; 95 \% \mathrm{CI}$ $0.31-0.50)$ and OS (HER2 positive: $\mathrm{HR}=0.36 ; 95 \% \mathrm{CI}$ $0.31-0.42)$. 
Table 2. Neoadjuvant trials with vertical blockade of the HER2 pathway

\begin{tabular}{|c|c|c|c|c|c|}
\hline Trial & Treatment arms & $\begin{array}{l}\text { Rate of pCR } \\
\text { (breast and/or } \\
\text { nodes), \% }\end{array}$ & $p$ value & $\mathrm{EFS} / \mathrm{PFS} / \mathrm{DFS}, \%$ & OS, \% \\
\hline \multirow{2}{*}{$\begin{array}{l}\text { GeparQuinto [15] } \\
\text { (phase } 3, n=620 \text { ) }\end{array}$} & EC/trastuzumab followed by docetaxel/trastuzumab & 30.3 & \multirow[t]{2}{*}{0.04} & 84.8 & 91.7 \\
\hline & EC/lapatinib followed by docetaxel/lapatinib & 22.7 & & 83.7 & 93.6 \\
\hline \multirow{4}{*}{$\begin{array}{l}\text { NeoALLTO }[16,17] \\
\text { (phase } 3, n=455 \text { ) }\end{array}$} & Trastuzumab followed by trastuzumab/paclitaxel & \multirow{2}{*}{\multicolumn{2}{|c|}{29.5}} & EFS ( 3 years) & \multirow[t]{2}{*}{90 (3 years) } \\
\hline & & & & 78 & \\
\hline & Lapatınıb followed by lapatınıb/paclitaxel & 24.7 & & 18 & 93 \\
\hline & $\begin{array}{l}\text { Trastuzumab/lapatinib followed by trastuzumab/ } \\
\text { lapatinib/paclitaxel }\end{array}$ & 51.3 & $\begin{array}{l}0.0001 \\
\text { (combination vs. } \\
\text { monotherapy) }\end{array}$ & 84 (ns) & 95 (ns) \\
\hline \multirow[t]{4}{*}{$\begin{array}{l}\text { CHER-LOB }[18,19] \\
\text { (phase } 2, n=121 \text { ) }\end{array}$} & $\begin{array}{l}\text { Trastuzumab/paclitaxel followed by FEC/ } \\
\text { trastuzumab }\end{array}$ & 25 & & 77.8 (ns) & \multirow{4}{*}{$\begin{array}{l}\text { OS pCR } \\
\text { vs. no pCR: } \\
97.2 \text { vs. } 80 \\
(p=0.028, \\
95 \% \text { CI } \\
0.02-1.08)\end{array}$} \\
\hline & Lapatinib/paclitaxel followed by FEC/lapatinib & 26.3 & & 78.1 & \\
\hline & Trastuzumab/lapatinib/paklitaxel followed by & 46.7 & 0.19 & 85.8 & \\
\hline & FEC/trastuzumao/rapatimo & & monotherapy) & & \\
\hline \multirow{3}{*}{$\begin{array}{l}\text { NSABP-B- } 41[20,21] \\
\text { (phase } 3, n=529 \text { ) }\end{array}$} & AC followed by trastuzumab/paclitaxel & 52.5 (breast) & & \multirow{3}{*}{$\begin{array}{l}84.3 \\
78.6 \\
90\end{array}$} & 94.5 \\
\hline & AC followed by lapatinib/paclitaxel & 53.2 & 0.9852 & & 89.4 \\
\hline & AC followed by trastuzumab/lapatinib/paclitaxel & 62 & 0.095 & & 95.7 \\
\hline \multirow{4}{*}{$\begin{array}{l}\text { CALBG } 40601[22,23] \\
\text { (phase } 3, n=305 \text { ) }\end{array}$} & Trastuzumab/paclitaxel & 46 (breast) & 0.13 & \multirow{4}{*}{$\begin{array}{l}\text { Significantly longer } \\
\text { IDFS in the } \\
\text { trastuzumab/lapatinib/ } \\
\text { paclitaxel arm } \\
(\mathrm{HR}=0.34 \\
95 \% \text { CI } 0.19-0.81 ; \\
p=0.01)\end{array}$} & \multirow[t]{4}{*}{ NA } \\
\hline & Lapatinib/paclitaxel & 32 & & & \\
\hline & Trastuzumab/lapatinib/paclitaxel & 56 & 0.11 & & \\
\hline & & & & & \\
\hline $\begin{array}{l}\text { DAFNE }[23,24] \\
\text { (phase } 2, n=65 \text { ) }\end{array}$ & $\begin{array}{l}6 \text { weeks of afatinib + trastuzumab followed by } \\
12 \text { weeks of paclitaxel, trastuzumab, and afatinib } \\
\text { followed by } 4 \text { cycles EC }\end{array}$ & 49.2 & NA & NA & NA \\
\hline \multirow{3}{*}{$\begin{array}{l}\text { NSABP FB-7 [25] } \\
\text { (phase } 2, n=126 \text { ) }\end{array}$} & Neratinib + paclitaxel followed by AC & 33 & \multirow[t]{3}{*}{ ns } & \multirow[t]{3}{*}{ NA } & \multirow[t]{3}{*}{ NA } \\
\hline & Trastuzumab + paclitaxel followed by AC & 38 & & & \\
\hline & $\begin{array}{l}\text { Trastuzumab + neratinib + paclitaxel followed } \\
\text { by AC }\end{array}$ & 50 & & & \\
\hline
\end{tabular}

NA, not available.

\section{Adjuvant Treatment}

The addition of trastuzumab to adjuvant chemotherapy reduces the risk of recurrence by approximately $40 \%$ and the risk of death by up to $30 \%$ [29-32]. According to pivotal trials and meta-analysis, the benefits of trastuzumab are independent of age, $\mathrm{T}$ and $\mathrm{N}$ stage, and hormone receptor status [31]. Importantly, real-word data confirmed a similar benefit [33]. Despite the significant impact on outcomes of trastuzumab introduction in the adjuvant setting, after a follow-up of 8-11 years, $15-24 \%$ of patients experienced disease recurrence [31]. To diminish the risk of recurrence further, many efforts have been made. One approach is extending the duration of anti-HER2 therapy (Table 3). For now, 2 strategies have been tested, i.e., trastuzumab for 2 years (HERA trial) and the sequential use of neratinib (irreversible pan-HER ty- rosine kinase inhibitor) after trastuzumab (ExteNET trial) $[29,34]$.

Among the pivotal trials, only the HERA trial evaluated 2 years of trastuzumab. At a median follow-up of 11 years, there was no additional benefit from the prolonged HER 2 blockade [3]. As expected, the rate of cardiac toxicity was higher in the 2 -year arm (7.3 vs. $4.4 \%)$ [3]. Following failure to improve outcomes and considering the increased toxicity as well as negative financial impacts, 2 years of adjuvant trastuzumab is not recommended.

Another treatment concept was evaluated in the ExteNET trial [34]. HER2-positive and disease-free patients after adjuvant chemotherapy and 1 year of trastuzumab were randomized to receiving neratinib or placebo for another year. After a 5 -year follow-up, the invasive DFS was 90.2 versus $87.7 \%(\mathrm{HR}=0.73$; $95 \%$ CI $0.57-0.92 ; p=$ 0.0083), respectively. Somewhat unexpectedly, the effect 
Table 3. Adjuvant treatment escalation

\begin{tabular}{|c|c|c|c|}
\hline Trial & Treatment arms & $\begin{array}{l}\text { Primary } \\
\text { endpoint }\end{array}$ & Trial results \\
\hline \multicolumn{4}{|c|}{ Extended duration of anti-HER2 therapy } \\
\hline $\begin{array}{l}\text { HERA [3] } \\
\text { (phase } 3, n=5,102 \text { ) }\end{array}$ & 2 years of trastuzumab vs. 1 year of trastuzumab & DFS & $\mathrm{HR}=1.02 ; 95 \% \mathrm{CI} 0.8-1.11$ \\
\hline $\begin{array}{l}\text { ExteNET [34] } \\
\text { (phase } 3, n=2,840 \text { ) }\end{array}$ & $\begin{array}{l}\text { Neratinib administered for } 1 \text { year after completion } \\
\text { of trastuzumab and chemotherapy }\end{array}$ & IDFS & $\mathrm{HR}=0.73 ; 95 \%$ CI $0.57-0.92 ; p=0.0083$ \\
\hline \multicolumn{4}{|l|}{ Dual HER2 blockade } \\
\hline $\begin{array}{l}\text { ALTTO }[35] \\
\text { (phase } 3, n=8,381)\end{array}$ & $\begin{array}{l}\text { Chemotherapy with trastuzumab, lapatinib, } \\
\text { trastuzumab/lapatinib, or trastuzumab and sequential } \\
\text { lapatinib }\end{array}$ & DFS & $\begin{array}{l}\text { Lapatinib/trastuzumab is not superior to trastuzumab } \\
(\mathrm{HR}=0.86 ; 95 \% \text { CI } 0.74-1.00) \\
\text { No difference was found when comparing } \\
\text { trastuzumab followed by lapatinib to trastuzumab } \\
(\mathrm{HR}=0.93 ; 95 \% \text { CI } 0.81-1.08)\end{array}$ \\
\hline \multicolumn{4}{|c|}{ - Dual blockade with trastuzumab and pertuzumab } \\
\hline $\begin{array}{l}\text { APHINITY }[38,39] \\
\text { (phase } 3, n=4,804 \text { ) }\end{array}$ & $\begin{array}{l}\text { Chemotherapy with pertuzumab/trastuzumab vs. } \\
\text { Chemotherapy with trastuzumab/placebo }\end{array}$ & IDFS & $\begin{array}{l}45 \text {-month follow up: } \\
\text { HR }=0.81 ; 95 \% \text { CI } 0.66-1.00 ; p=0.045 \\
\text { For node-positive patients: } \\
\text { HR }=0.77 ; p=0.019 \\
6 \text {-year follow-up: } \\
\text { HR }=0.72 ; 95 \% \text { CI } 0.59-0.87\end{array}$ \\
\hline \multicolumn{4}{|c|}{ Combination of anti-HER2 agents, including T-DM1 } \\
\hline $\begin{array}{l}\text { KAITLIN [42] } \\
\text { (phase } 3, n=1,846)\end{array}$ & $\begin{array}{l}3-4 \text { cycles of anthracycline-based chemotherapy } \\
\text { and then randomization: TDM1/pertuzumab vs. } \\
\text { taxane/pertuzumab/trastuzumab }\end{array}$ & IDFS & $\mathrm{HR}=0.98 ; 95 \% \mathrm{CI} 0.72-1.32 ; p=0.8270$ \\
\hline $\begin{array}{l}\text { KATHERINE [41] } \\
\text { (phase } 3, n=1,468)\end{array}$ & $\begin{array}{l}\text { Patients with residual disease after neoadjuvant } \\
\text { chemotherapy and trastuzumab received } 14 \text { cycles of } \\
\text { T-DM1 or } 14 \text { cycles of trastuzumab }\end{array}$ & IDFS & $\mathrm{HR}=0.50 ; 95 \%$ CI $0.39-0.64$ \\
\hline
\end{tabular}

was greater in the hormone receptor-positive group, most likely due to the bidirectional cross-talk between estrogen receptors and HER2 receptors. For now, an additional year of anti-HER2 therapy with neratinib after 1 year of trastuzumab only as anti-HER2 therapy should be considered for high-risk hormone receptor-positive patients.

The addition of another anti-HER2 drug, such as lapatinib, to trastuzumab in a concurrent or sequential manner was tested in the ALTTO trial [35]. Patients who did not receive adjuvant trastuzumab were randomized in the TEACH trial to receiving 1 year of placebo or lapatinib [36]. Another attempt to improve the results was the addition of the anti-VEGF antibody bevacizumab to trastuzumab (BETH trial) [37]. Unfortunately, none of those 3 concepts showed a significant benefit in terms of DFS or OS improvement.

In the adjuvant setting, in the APHINITY trial, 4,800 HER2-positive breast cancer patients were randomized to receiving chemotherapy/trastuzumab and pertuzumab or chemotherapy/trastuzumab and placebo [38]. Invasive DFS, the primary endpoint of the trial, was met. The results favored the pertuzumab arm (94.1 vs. $93.2 \%$; HR = $0.81 ; p=0.045)$. Updated APHINITY trial results showed the continuation of a clear benefit in the 6-year invasive DFS (87.9\% with pertuzumab and $83.4 \%$ with placebo; $\mathrm{HR}=0.72$; 95\% CI 0.59-0.87) in node-positive patients [39]. Despite the fact that APHINITY is a positive trial, it is important to outline that the addition of pertuzumab portends only a small benefit to the overall population and a more significant benefit to high-risk, lymph nodepositive patients, and it should be advised for that group of patients only.

For now, there are no clear guidelines for the use of adjuvant pertuzumab after its neoadjuvant use, especially for patients who achieved a pCR. The majority of neoadjuvant pertuzumab trials consisted of the single agent trastuzumab in the adjuvant setting. Only in the BERENICE trial did patients continue to receive a dual blockade with an adjuvant [40]. Based on the results of neoadjuvant trials with pertuzumab use as well as the APHINITY study, for now, adjuvant pertuzumab after its neoadjuvant use should be administered only to high-risk patients with positive lymph nodes.

For patients with residual disease after neoadjuvant therapy, T-DM1 should be administered, rather than pertuzumab with trastuzumab. This recommendation is 
Table 4. Adjuvant treatment deescalation

\begin{tabular}{|c|c|c|c|}
\hline Trial & Treatment arms & Primary endpoint & Results \\
\hline \multicolumn{4}{|c|}{ Shorter adjuvant anti-HER2 therapy } \\
\hline $\begin{array}{l}\text { FinHer }[46] \\
(n=1,010, \text { phase } 3)\end{array}$ & $\begin{array}{l}3 \text { cycles docetaxel or vinorelbine, followed in both arms by } 3 \text { cycles } \\
\text { of FEC; HER2-positive patients were further assigned to receiving } \\
\text { trastuzumab for } 9 \text { weeks with docetaxel or vinorelbine }\end{array}$ & RFS & $\begin{array}{l}\text { HER2-positive subgroup: } \\
89 \text { vs. } 78 \% ; \mathrm{HR}=0.42 ; \\
95 \% \text { CI } 0.21-0.83 ; p=0.01\end{array}$ \\
\hline $\begin{array}{l}\text { PERSEPHONE }[50] \\
(n=4,088, \text { phase } 3)\end{array}$ & $\begin{array}{l}\text { Chemotherapy of the physician's choice }+ \text { trastuzumab for } 6 \text { vs. } 12 \\
\text { months }\end{array}$ & 2-year DFS & $\begin{array}{l}89.4 \text { vs. } 89.8 \% ; \mathrm{HR}=1.28 \\
95 \% \text { CI } 0.93-1.24 \\
\text { noninferiority margin: } 1.29\end{array}$ \\
\hline $\begin{array}{l}\text { PHARE }[48] \\
(n=3,380, \text { phase } 3)\end{array}$ & Chemotherapy followed trastuzumab for 6 vs. 12 months & 2-year DFS & $\begin{array}{l}91.1 \text { vs. } 93.8 \% ; \mathrm{HR}=1.28 \\
95 \% \text { CI } 0.1 .05-1.56 ; p=0.39 \\
\text { noninferiority margin: } 1.15\end{array}$ \\
\hline $\begin{array}{l}\text { SOLD [47] } \\
(n=2,174, \text { phase } 3)\end{array}$ & $\begin{array}{l}\text { Docetaxel/trastuzumab for } 9 \text { weeks followed by FEC vs. docetaxel/ } \\
\text { trastuzumab for } 9 \text { weeks followed by FEC followed by trastuzumab } \\
\text { for up to } 1 \text { year }\end{array}$ & 5-year DFS & $\begin{array}{l}85.4 \text { vs. } 87.5, \mathrm{HR}=1.39 \\
\text { 2-sided } 90 \% \text { CI } 1.12-1.72 ; \\
\text { noninferiority margin: } 1.38\end{array}$ \\
\hline $\begin{array}{l}\text { ShortHER [51] } \\
(n=1,253 \text {, phase } 3)\end{array}$ & $\begin{array}{l}3 \text { cycles of docetaxel + weekly trastuzumab ( } 9 \text { weeks) followed by } \\
\text { FEC vs. doxorubicine/cyclophosphamide followed by thrice weekly } \\
\text { docetaxel with trastuzumab followed by trastuzumab for up to } 1 \text { year }\end{array}$ & 5-year DFS & $\begin{array}{l}85.4 \text { vs. } 87.5 \% ; \mathrm{HR}=1.15 \\
95 \% \text { CI } 0.91-1.46 ; \\
\text { noninferiority margin: } 1.29\end{array}$ \\
\hline $\begin{array}{l}\text { HORG }[49] \\
(n=481, \text { phase } 3)\end{array}$ & $\begin{array}{l}\text { Dose-dense FEC followed by dose-dense docetaxel + trastuzumab } \\
\text { for } \\
6 \text { months vs. dose-dense FEC followed by dose-dense docetaxel + } \\
\text { trastuzumab for } 12 \text { months }\end{array}$ & 3-year DFS & $\begin{array}{l}85.4 \text { vs. } 87.5 \% ; \mathrm{HR}=1.57 \\
95 \% \text { CI } 0.086-2.10 ; p=0.137 ; \\
\text { noninferiority margin: } 1.53\end{array}$ \\
\hline \multicolumn{4}{|c|}{ Deescalating chemotherapy/anthracycline-free chemotherapy } \\
\hline $\begin{array}{l}\text { APT }[44] \\
(n=406, \text { phase } 2)\end{array}$ & Paclitaxel (12 weeks) concurrent with trastuzumab for 1 year & 3-year DFS & $\begin{array}{l}98.7 \% \text {; in updated analyses at } \\
7 \text { years the DFS was } 93.3 \%\end{array}$ \\
\hline $\begin{array}{l}\text { ATEMPT }[45] \\
(n=497, \text { phase } 2)\end{array}$ & $\begin{array}{l}\text { T-DM1 vs. paclitaxel (12 weeks) concurrent with trastuzumab for } \\
1 \text { year }\end{array}$ & $\begin{array}{l}\text { Clinically relevant } \\
\text { toxicity, coprimary } \\
\text { endpoint: 3-year DFS }\end{array}$ & $\begin{array}{l}98.7 \text { vs. } 92.8 \% \\
\text { The study was not powered to } \\
\text { estimate an efficacy difference }\end{array}$ \\
\hline
\end{tabular}

based on the KATHERINE trial results [41]. In the randomized phase 3 trial, 1,468 HER2-positive patients with residual disease after neoadjuvant taxane-containing chemotherapy and trastuzumab or dual blockade were randomized to receiving 14 cycles of trastuzumab or 14 cycles of T-DM1. T-DM1 administration improved invasive disease-free survival (IDFS) ( 88 vs. $77 \%$; $\mathrm{HR}=0.50$; 95\% CI 0.39-0.64). The benefit of T-DM1 compared to trastuzumab was similar, regardless of the preoperative choice of anti-HER2 therapy. The most common adverse events leading to treatment discontinuation were thrombocytopenia (4.2\%), hyperbilirubinemia (2.6\%), and elevation of alanine transaminase (1\%).

We are witnessing continued improvement in our understanding of breast cancer tumor biology and, based on the advances in our ability to further personalize, individualized therapeutic approaches to patients with HER2-positive early breast cancer. Generally, there are 2 main trends, i.e., treatment deescalation and treatment escalation.

Conventional chemotherapy is associated with systemic toxicity, so more effective, less toxic treatments are needed. In the KAITLIN trial, patients were randomly assigned within 9 weeks of surgery to receiving 3-4 cycles of anthracycline-based chemotherapy followed by $18 \mathrm{cy}-$ cles of T-DM1 plus pertuzumab or a combination of 12 weeks of taxane and pertuzumab and trastuzumab for up to 1 year [42]. The primary endpoint (IDFS) was not met $(\mathrm{HR}=0.98 ; 95 \%$ CI $0.72-1.32 ; p=0.8270)$.

In addition to tumor biology, tumor size might be a potential criterion to select a subpopulation of patients who might benefit from less intensive treatment. According to a retrospective analysis, even small tumors have a significant risk of recurrence (10-30\%) [43]. On the other hand, the majority of pivotal trials did not include patients with tumors $<2 \mathrm{~cm}$ in diameter [31].

Deescalation phase 2 of a non-randomized APT trial included HER2-positive tumors $<3 \mathrm{~cm}$ without lymph node involvement [44]. Patients received 12 weeks of paclitaxel plus trastuzumab and then trastuzumab to complete 1 year. In the updated analyses at 7 years, the DFS was $93.3 \%$, with a $97.5 \%$ recurrence-free interval. Generally, paclitaxel-trastuzumab is a preferred regimen for tumors $<2 \mathrm{~cm}$, although there is no phase 3 comparison of that protocol with other regimens.

In the ATEMPT trial, the adjuvant T-DM1 was tested in a similar population. In that phase 2 trial, patients with 
stage 1 HER2-positive breast cancer were randomized to receiving T-DM1 or paclitaxel-trastuzumab at a 3:1 ratio [45]. The 3-year DFS was $97.7 \%$ for the T-DM1 arm and $92.8 \%$ for paclitaxel/trastuzumab, but the study was not powerful enough to estimate the efficacy difference between the 2 study arms [45]. The toxicity profile incidence was similar between the 2 groups. For now, T-DM1 is not accepted as a standard adjuvant regimen for this population.

For low-risk HER2 tumors, a shorter trastuzumab administration was tested in our attempt to decrease cardiotoxicity and lower the financial burden of anti-HER2 therapy. The oldest one was FinHER, with 9 weeks of adjuvant trastuzumab versus observation, which showed a $58 \%$ reduction of the risk of death $(p=0.01)$ [46]. In the SOLD trial, investigators compared 9 weeks versus 1 year of adjuvant trastuzumab [47]. This noninferiority trial did not show that 9 weeks was as good as 1 year $(5$-year DFS: 88.0 vs. $90.5 \%$, respectively; $\mathrm{HR}=1.39 ; 2$-sided $90 \%$ CI 1.12-1.72). Other noninferiority trials, such as PHARE, HORG, and PERSEPHONE, compared 6 months versus 1 year of adjuvant trastuzumab treatment [48-50]. Neither the PHARE trial $(\mathrm{HR}=1.08$; 95\% CI $0.93-1.25$; $p=$ $0.39)$ nor the HORG trial showed noninferiority ( $\mathrm{HR}=$ 1.57 ; $95 \%$ CI $0.86-2.10 ; p=0.137$ ). Only the PERSEPHONE trial showed noninferiority (89.4 vs. 89.9\%; $\mathrm{HR}=1.07$; 95\% CI 0.93-1.24; Table 4) [50]. Cardiotoxicity was higher in frequency in the 12-month group compared with the 6-month group, although the incidence was low and reversible. A conclusion of our attempts to shorten the length of adjuvant trastuzumab use is that 1 year remains the standard and, if needed, because of toxicity or other reasons, we can stop trastuzumab early without damaging the interests of our patients significantly. ment of patients with early HER2-positive breast cancer. Introduction of a dual blockade in the neoadjuvant setting improved the rate of $\mathrm{pCR}$, which translated to better long-term outcomes. The benefit of dual anti-HER2 blockade in the adjuvant setting with either pertuzumab mended for small, node-negative, HER2-positive tumors.

Despite significant improvement in HER2-positive early breast cancer treatment, there are still unanswered questions. Biologic heterogeneity within HER2-positive breast cancer requires further investigation in order to develop valid biomarkers that will lead to a better definition of different risk subgroups of patients who might benefit from different treatment strategies.

\section{Conflict of Interest Statement}

Marija Ban: speaker fees (Amgen, Novartis, Pfizer, Roche, and Merck). Eduard Vrdoljak: support for clinical trials and scientific projects (Pfizer, Roche, BMS, and AZ) and speaker fees and consulting (Amgen, Astellas, Astra Zeneca, Boehringer Ingelheim, Johnson \& Johnson, Novartis, PharmaSwiss, Pfizer, Roche, Sanofi, MSD, and Merck). Branka Petrić Miše: Speaker fees and consulting (Amgen, Astra Zeneca, BMS, Novartis, Pfizer, Roche, Sanofi, and MSD).

\section{Funding Sources}

There are no funding sources.

\section{Author Contributions}

M.B. contributed to the literature search and analysis, defining the structure of the article, the writing of this article, critical review of this article and corrections, and administrative work such as paper submission and correspondence with authorities. B.P.M. contributed to the literature search and analysis, the writing of this article, and critical review of this article and corrections. E.V. contributed to the literature search and analysis, defining the article design, the writing of this article, critical review of article, article revision, and supervision.

\section{Conclusion}

Trastuzumab has changed the landscape of the treator neratinib added to trastuzumab has shown modest improvement in DFS. Dual inhibition with trastuzumab and pertuzumab should be reserved for lymph node-positive patients only. The use of T-DM1 in patients with residual disease after neoadjuvant treatment has shown significant benefits in IDFS. For now, chemotherapy deescalation in combination with trastuzumab should be recom-

\section{References}

1 Slamon DJ, Clark GM, Wong SG, Levin WJ, Ullrich A, McGuire WL. Human breast cancer: correlation of relapse and survival with amplification of the HER-2/neu oncogene. Science. 1987 Jan;235(4785):177-82.

2 Slamon DJ, Leyland-Jones B, Shak S, Fuchs H, Paton V, Bajamonde A, et al. Use of chemotherapy plus a monoclonal antibody against HER2 for metastatic breast cancer that overexpresses HER2. N Engl J Med. 2001 Mar; 344(11):783-92.

3 Cameron D, Piccart-Gebhart MJ, Gelber RD, Procter M, Goldhirsch A, de Azambuja E, et al.; Herceptin Adjuvant (HERA) Trial Study Team. 11 years' follow-up of trastuzumab after adjuvant chemotherapy in HER2-positive early breast cancer: final analysis of the HERceptin Adjuvant (HERA) trial. Lancet. 2017 Mar;389(10075):1195-205.

4 Pernas S, Barroso-Sousa R, Tolaney SM. Optimal treatment of early stage HER2-positive breast cancer. Cancer. 2018 Dec;124(23): 4455-66. 
5 Wuerstlein R, Harbeck N. Neoadjuvant Therapy for HER2-positive Breast Cancer. Rev Recent Clin Trials. 2017;12(2):81-92.

6 Buzdar AU, Ibrahim NK, Francis D, Booser DJ, Thomas ES, Theriault RL, et al. Significantly higher pathologic complete remission rate after neoadjuvant therapy with trastuzumab, paclitaxel, and epirubicin chemotherapy: results of a randomized trial in human epidermal growth factor receptor 2-positive operable breast cancer. J Clin Oncol. 2005 Jun;23(16):3676-85.

7 Gianni L, Eiermann W, Semiglazov V, Manikhas A, Lluch A, Tjulandin S, et al. Neoadjuvant chemotherapy with trastuzumab followed by adjuvant trastuzumab versus neoadjuvant chemotherapy alone, in patients with HER2-positive locally advanced breast cancer (the NOAH trial): a randomised controlled superiority trial with a parallel HER2-negative cohort. Lancet. 2010 Jan;375(9712):377-84.

8 Untch M, Rezai M, Loibl S, Fasching PA Huober J, Tesch H, et al. Neoadjuvant treatment with trastuzumab in HER2-positive breast cancer: results from the GeparQuattro study. J Clin Oncol. 2010 Apr;28(12):2024-31.

9 Schneeweiss A, Chia S, Hickish T, Harvey V, Eniu A, Hegg R, et al. Pertuzumab plus trastuzumab in combination with standard neoadjuvant anthracycline-containing and anthracycline-free chemotherapy regimens in patients with HER2-positive early breast cancer: a randomized phase II cardiac safety study (TRYPHAENA). Ann Oncol. 2013 Sep;24(9): 2278-84.

10 Gianni L, Pienkowski T, Im YH, Tseng LM, Liu MC, Lluch A, et al. 5-year analysis of neoadjuvant pertuzumab and trastuzumab in patients with locally advanced, inflammatory, or early-stage HER2-positive breast cancer (NeoSphere): a multicentre, open-label, phase 2 randomised trial. Lancet Oncol. 2016 Jun; 17(6):791-800

11 Hofmann D, Nitz U, Gluz O, Kates RE, Schinkoethe T, Staib P, et al. WSG ADAPT adjuvant dynamic marker-adjusted personalized therapy trial optimizing risk assessment and therapy response prediction in early breast cancer: study protocol for a prospective, multi-center, controlled, non-blinded, randomized, investigator initiated phase II/ III trial. Trials. 2013 Aug;14(1):261.

12 Hurvitz SA, Martin M, Symmans WF, Jung $\mathrm{KH}$, Huang CS, Thompson AM, et al. Neoadjuvant trastuzumab, pertuzumab, and chemotherapy versus trastuzumab emtansine plus pertuzumab in patients with HER2-positive breast cancer (KRISTINE): a randomised, open-label, multicentre, phase 3 trial. Lancet Oncol. 2018 Jan;19(1):115-26.

13 Harbeck N. Insights into biology of luminal HER2 vs. enriched HER2 subtypes: therapeutic implications. Breast. 2015 Nov;24(Suppl 2):S44-8.

14 Clavarezza M, Puntoni M, Gennari A, Paleari L, Provinciali N, D'Amico M, et al. Dual Block with Lapatinib and Trastuzumab Versus Single-Agent Trastuzumab Combined with Chemotherapy as Neoadjuvant Treatment of HER2-Positive Breast Cancer: A Meta-analysis of Randomized Trials. Clin Cancer Res. 2016 Sep;22(18):4594-603.
15 Untch M, von Minckwitz G, Gerber B, Schem C, Rezai M, Fasching PA, et al.; GBG and the AGO-B Study Group. Survival Analysis After Neoadjuvant Chemotherapy With Trastuzumab or Lapatinib in Patients With Human Epidermal Growth Factor Receptor 2-Positive Breast Cancer in the GeparQuinto (G5) Study (GBG 44). J Clin Oncol. 2018 May; 36(13):1308-16

16 Baselga J, Bradbury I, Eidtmann H, Di Cosimo S, de Azambuja E, Aura C, et al.; NeoALTTO Study Team. Lapatinib with trastuzumab for HER2-positive early breast cancer (NeoALTTO): a randomised, open-label, multicentre, phase 3 trial. Lancet. 2012 Feb; 379(9816):633-40.

17 de Azambuja E, Holmes AP, Piccart-Gebhart M, Holmes E, Di Cosimo S, Swaby RF, et al. Lapatinib with trastuzumab for HER2-positive early breast cancer (NeoALTTO): survival outcomes of a randomised, open-label, multicentre, phase 3 trial and their association with pathological complete response. Lancet Oncol. 2014 Sep;15(10):1137-46.

18 Guarneri V, Frassoldati A, Bottini A, Cagossi K, Bisagni G, Sarti S, et al. Preoperative chemotherapy plus trastuzumab, lapatinib, or both in human epidermal growth factor receptor 2-positive operable breast cancer: results of the randomized phase II CHER-LOB study. J Clin Oncol. 2012 Jun;30(16):1989-95.

19 Guarneri V, Dieci M, Bisagni G, Generali D, Cagossi K, Sarti S, et al. Survival analysis of the prospective randomized Cher-Lob study evaluating the dual anti-HER2 treatment with trastuzumab and lapatinib plus chemotherapy as neoadjuvant therapy for HER2-positive breast cancer (BC). J Clin Oncol. 2020 May; 38(15_suppl):582-82.

20 Swain SM, Tang G, Brauer HA, Goerlitz DS, Lucas PC, Robidoux A, et al. NSABP B-41, a Randomized Neoadjuvant Trial: Genes and Signatures Associated with Pathologic Complete Response. Clin Cancer Res. 2020 Aug; 26(16):4233-41.

21 Robidoux A, Tang G, Rastogi P, Geyer CE, Azar CA, Atkins JR, et al. Evaluation of lapatinib as a component of neoadjuvant therapy for HER2+ operable breast cancer: 5-year outcomes of NSABP protocol B-41. J Clin Oncol. 2016 May;34(15_suppl):501-01.

22 Carey LA, Berry DA, Cirrincione CT, Barry WT, Pitcher BN, Harris LN, et al. Molecular Heterogeneity and Response to Neoadjuvant Human Epidermal Growth Factor Receptor 2 Targeting in CALGB 40601, a Randomized Phase III Trial of Paclitaxel Plus Trastuzumab With or Without Lapatinib. J Clin Oncol. 2016 Feb;34(6):542-9.

23 Krop IE, Hillman D, Polley MY, Tanioka M, Parker J, Huebner L, et al. Abstract GS3-02: Invasive disease-free survival and gene expression signatures in CALGB (Alliance) 40601, a randomized phase III neoadjuvant trial of dual HER2-targeting with lapatinib added to chemotherapy plus trastuzumab. Cancer Res. 2018 Feb; 78(4 Supplement):GS3-02.

24 Hanusch C, Schneeweiss A, Loibl S, Untch M, Paepke S, Kümmel S, et al. Dual Blockade with AFatinib and Trastuzumab as NEoadjuvant Treatment for Patients with Locally Ad- vanced or Operable Breast Cancer Receiving Taxane-Anthracycline Containing Chemotherapy-DAFNE (GBG-70). Clin Cancer Res. 2015 Jul;21(13):2924-31.

25 Jacobs SA, Robidoux A, Garcia JMP, Abraham J, La Verde N, Orcutt JM, et al. Abstract PD5-04: NSABP FB-7: A phase II randomized trial evaluating neoadjuvant therapy with weekly paclitaxel $(\mathrm{P})$ plus neratinib $(\mathrm{N})$ or trastuzumab $(\mathrm{T})$ or neratinib and trastuzumab $(\mathrm{N}+\mathrm{T})$ followed by doxorubicin and cyclophosphamide (AC) with postoperative $\mathrm{T}$ in women with locally advanced HER2-positive breast cancer. Cancer Res. 2016 Feb; 76(4):PD5-04.

26 Park JW, Liu MC, Yee D, Yau C, van 't Veer LJ, Symmans WF, et al.; I-SPY 2 Investigators. Adaptive Randomization of Neratinib in Early Breast Cancer. N Engl J Med. 2016 Jul; 375(1):11-22.

27 von Minckwitz G, Untch M, Blohmer JU, Costa SD, Eidtmann H, Fasching PA, et al. Definition and impact of pathologic complete response on prognosis after neoadjuvant chemotherapy in various intrinsic breast cancer subtypes. J Clin Oncol. 2012 May;30(15): 1796-804.

28 Cortazar P, Zhang L, Untch M, Mehta K, Costantino JP, Wolmark N, et al. Pathological complete response and long-term clinical benefit in breast cancer: the CTNeoBC pooled analysis. Lancet. 2014 Jul;384(9938):164-72.

29 Piccart-Gebhart MJ, Procter M, LeylandJones B, Goldhirsch A, Untch M, Smith I, et al.; Herceptin Adjuvant (HERA) Trial Study Team. Trastuzumab after adjuvant chemotherapy in HER2-positive breast cancer. $\mathrm{N}$ Engl J Med. 2005 Oct;353(16):1659-72.

30 Romond EH, Perez EA, Bryant J, Suman VJ, Geyer CE Jr, Davidson NE, et al. Trastuzumab plus adjuvant chemotherapy for operable HER2-positive breast cancer. N Engl J Med. 2005 Oct;353(16):1673-84.

31 Moja L, Tagliabue L, Balduzzi S, Parmelli E, Pistotti V, Guarneri V, et al. Trastuzumab containing regimens for early breast cancer. Cochrane Database Syst Rev. 2012 Apr;(4):CD006243.

32 Slamon DJ, Eiermann W, Robert NJ, Giermek J, Martin M, JasiĂłwka M, et al. Abstract S504: ten year follow-up of BCIRG-006 comparing doxorubicin plus cyclophosphamide followed by docetaxel (AC-T) with doxorubicin plus cyclophosphamide followed by docetaxel and trastuzumab (AC-TH) with docetaxel, carboplatin and trastuzumab (TCH) in HER2+ early breast cancer. Cancer Res. 2016 Feb;76(4):S5-04.

33 Ban M, Viculin J, Tomic S, Capkun V, Strikic A, Mise BP, et al. Retrospective analysis of efficacy of trastuzumab in adjuvant treatment of HER 2 positive early breast cancer - single institution experience. Neoplasma. 2016; 63(5):761-7.

34 Martin M, Holmes FA, Ejlertsen B, Delaloge S, Moy B, Iwata H, et al.; ExteNET Study Group. Neratinib after trastuzumab-based adjuvant therapy in HER2-positive breast cancer (ExteNET): 5-year analysis of a randomised, double-blind, placebo-controlled, phase 3 trial. Lancet Oncol. 2017 Dec;18(12): 1688-700. 
35 Piccart-Gebhart M, Holmes E, Baselga J, de Azambuja E, Dueck AC, Viale G, et al. Adjuvant lapatinib and trastuzumab for early HER2-positive breast cancer: results from the randomized phase III adjuvant lapatinib and/ or trastuzumab treatment optimization trial. J Clin Oncol. 2016 Apr;34:1034-42.

36 Goss PE, Smith IE, O’Shaughnessy J, Ejlertsen B, Kaufmann M, Boyle F, et al.; TEACH investigators. Adjuvant lapatinib for women with early-stage HER2-positive breast cancer: a randomised, controlled, phase 3 trial. Lancet Oncol. 2013 Jan;14(1):88-96.

37 Slamon DJ, Swain SM, Buyse M, Martin M, Geyer CE, Im Y-H, et al. Primary results from $\mathrm{BETH}$, a phase 3 controlled study of adjuvant chemotherapy and trastuzumab \pm bevacizumab in patients with HER2-positive, nodepositive, or high-risk node-negative breast cancer. Cancer Res. 2013 Dec;73(24):S1-03.

38 von Minckwitz G, Procter M, de Azambuja E Zardavas D, Benyunes M, Viale G, et al.; APHINITY Steering Committee and Investigators. Adjuvant Pertuzumab and Trastuzumab in Early HER2-Positive Breast Cancer. N Engl J Med. 2017 Jul;377(2):122-31.

39 Piccart M, Procter M, Fumagalli D, de Azambuja E, Clark E, Michael S, et al. Interim overall survival analysis of APHINITY (BIG 4-11): a randomized, multicenter, double blind, placebo controlled trial comparing chemotherapy plus trastuzumab plus pertuzumab vs chemotherapy plus trastuzumab plus placebo as adjuvant therapy in patients with operable HER-2 positive early breast cancer. Cancer Res. 2020 Feb;80(4):GS1-04.

40 Swain SM, Ewer MS, Viale G, Delaloge S, Ferrero JM, Verrill M, et al.; BERENICE Study Group. Pertuzumab, trastuzumab, and standard anthracycline- and taxane-based chemotherapy for the neoadjuvant treatment of patients with HER2-positive localized breast cancer (BERENICE): a phase II, open-label, multicenter, multinational cardiac safety study. Ann Oncol. 2018 Mar;29(3):646-53.
41 von Minckwitz G, Huang CS, Mano MS, Loibl S, Mamounas EP, Untch M, et al.; KATHERINE Investigators. Trastuzumab Emtansine for Residual Invasive HER2-Positive Breast Cancer. N Engl J Med. 2019 Feb;380(7):617-28.

42 Harbeck N, Ah-Im S, Barrios CH, Herve R, Gralow J, Toi M, et al. Primary analysis of KAITLIN: A phase III study of trastuzumab emtansine (T-DM1) + pertuzumab versus trastuzumab + pertuzumab + taxane, after anthracyclines as adjuvant therapy for high-risk HER2-positive early breast cancer (EBC). J Clin Oncol. 2020;38(15_suppl):500.

43 Gonzalez-Angulo AM, Litton JK, Broglio KR, Meric-Bernstam F, Rakkhit R, Cardoso F, et al. High risk of recurrence for patients with breast cancer who have human epidermal growth factor receptor 2-positive, node-negative tumors $1 \mathrm{~cm}$ or smaller. J Clin Oncol. 2009 Dec;27:5700-6.

44 Tolaney SM, Guo H, Pernas S, Barry WT, Dillon DA, Ritterhouse L, et al. Seven-Year Follow-Up Analysis of Adjuvant Paclitaxel and Trastuzumab Trial for Node-Negative, Human Epidermal Growth Factor Receptor 2-Positive Breast Cancer. J Clin Oncol. 2019 Aug;37(22):1868-75.

45 Tolaney SM TL, Berry W, et al. TBCRC 033: A randomized phase II study of adjuvant trastuzumab emtansine (T-DM1) vs paclitaxel $(\mathrm{T})$ in combination with trastuzumab $(\mathrm{H})$ for stage I HER2-positive breast cancer (BC) (ATEMPT). San Antonio Breast Cancer Symposium; 2019 Dec 9-12; San Antonio, TX.

46 Joensuu H, Bono P, Kataja V, Alanko T, Kokko R, Asola R, et al. Fluorouracil, epirubicin, and cyclophosphamide with either docetaxel or vinorelbine, with or without trastuzumab, as adjuvant treatments of breast cancer: final results of the FinHer Trial. J Clin Oncol. 2009 Dec;27(34):5685-92.
47 Joensuu H, Fraser J, Wildiers H, Huovinen R, Auvinen P, Utriainen M, et al. Effect of adjuvant trastuzumab for a duration of 9 weeks vs 1 year with concomitant chemotherapy for early human epidermal growth factor receptor 2-positive breast cancer: the sold randomized clinical trial. JAMA Oncol. 2018 Sep; 4(9):1199-206.

48 Pivot X, Romieu G, Debled M, Pierga JY, Kerbrat $\mathrm{P}$, Bachelot T, et al.; PHARE trial investigators. 6 months versus 12 months of adjuvant trastuzumab for patients with HER2positive early breast cancer (PHARE): a randomised phase 3 trial. Lancet Oncol. 2013 Jul;14(8):741-8.

49 Mavroudis D, Saloustros E, Malamos N, Kakolyris S, Boukovinas I, Papakotoulas P, et al.; Breast Cancer Investigators of Hellenic Oncology Research Group (HORG), Athens, Greece. Six versus 12 months of adjuvant trastuzumab in combination with dose-dense chemotherapy for women with HER2-positive breast cancer: a multicenter randomized study by the Hellenic Oncology Research Group (HORG). Ann Oncol. 2015 Jul;26(7): 1333-40.

50 Earl HM, Hiller L, Vallier AL, Loi S, McAdam K, Hughes-Davies L, et al.; PERSEPHONE Steering Committee and Trial Investigators. 6 versus 12 months of adjuvant trastuzumab for HER2-positive early breast cancer (PERSEPHONE): 4-year disease-free survival results of a randomised phase 3 non-inferiority trial. Lancet. 2019 Jun;393(10191): 2599-612.

51 Conte PF, Bisagni G, Frassoldati A, Brandes AA, Anselmi E, Giotta F, et al. 9 weeks vs 1 year adjuvant trastuzumab in combination with chemotherapy: results of the phase III multicentric Italian study Short-HER. J Clin Oncol. 2017 May;35(15_suppl):501. 